\title{
Laparoscopic surgery in adults with transposition of the great arteries: A report of two cases
}

\author{
Margaret Mariella BA' ${ }^{1}$, T. Max Gevedon BS ${ }^{1}$, Sean Clifford MD ${ }^{2}$, Jaipeng Huang MD ${ }^{2}$, Erica Sutton MD ${ }^{1}$ and Hiram C. PolkJr. MD ${ }^{1}$ \\ ${ }^{1}$ Department of Surgery, University of Louisville School of Medicine, Louisville, KY, USA \\ ${ }^{2}$ Department of Anesthesiology and Perioperative Medicine, University of Louisville School of Medicine, Louisville, KY, USA
}

\section{Background}

The number of adult patients with congenital heart disease (CHD) is increasing in all developed countries, due in part to improved intrauterine diagnosis, neonatal intensive care advances, and improved surgical repair techniques [1]. Consequently, more adult CHD patients are presenting for elective, noncardiac surgery. However, adult CHD patients experience increased morbidity and mortality when undergoing noncardiac procedures as compared to their matched counterparts, adding increased importance to the preoperative assessment, intraoperative management of patient physiology, and postoperative monitoring [2,3]. Here, we examine two cases of adult patients with corrected Transposition of the Great Arteries (TGA) who underwent laparoscopic inguinal hernia repair and cholecystectomy.

\section{Case presentations}

Patient 1 is a 77-year-old male formerly under the care of Dr. Helen Taussig for congenital correction of TGA who presented with longstanding but increasingly symptomatic groin discomfort. His physical exam was consistent with a reducible right inguinal hernia and negative for clinical signs of heart failure. Echocardiogram demonstrated normal left ventricle size and function and a small membranous VSD, trace mitral regurgitation and a prominent papillary muscle. He underwent an uncomplicated laparoscopic bilateral inguinal hernia repair. Anesthesia was induced with propofol and etomidate. Neither a central venous catheter nor arterial catheter was used for intraoperative monitoring. Pneumoperitoneum was limited at $15 \mathrm{~cm} \mathrm{H}_{2} \mathrm{O}$. He experienced an uneventful post-operative course with complete resolution of his groin discomfort and return to all normal activities six weeks after surgery.

Patient 2 is a 34-year-old male with a history of surgically corrected TGA who presented with bloating, postprandial nausea, and colicky right upper quadrant pain. He underwent placement of an atrial baffle on day of life two for correction of his TGA. His physical exam was consistent with biliary colic and negative for clinical signs of heart failure. Right upper quadrant ultrasound revealed cholelithiasis, with a $4.5 \mathrm{~mm}$ stone present in the cystic duct. Echocardiogram showed a severely dilated right ventricle with moderately to severely decreased function, with posterior bowing of the ventricular septum producing a "pancaking" effect on the left ventricle. There was also evidence of stable mild to moderate aortic valve insufficiency. Pulmonary function testing one month prior to presentation revealed a mild obstructive lung defect, with faint wheezes. The patient's $\mathrm{SaO}_{2}$ was $98 \%$ on room air though he complained of exertional dyspnea. He underwent an uncomplicated laparoscopic cholecystectomy. Anesthesia was induced with propofol and etomidate. Intraoperative monitoring was aided by an arterial catheter and central venous pressure monitor. Pneumoperitoneum was limited at $15 \mathrm{~cm} \mathrm{H_{2 }} \mathrm{O}$. He experienced an uneventful post-surgical course, with complete resolution of his nausea, vomiting, and right upper quadrant pain at one-month follow-up.

\section{Discussion}

For clinicians performing laparoscopic procedures on adult CHD patients, perioperative assessment and management may reduce morbidity and mortality and lead to improve outcomes. Collaboration between the patient's surgeon, anesthesiologist, and cardiologist is valuable before and during the procedure, as is obtaining a thorough history from the patient, including symptoms associated with his or her condition [4-6]. Preoperative laboratory testing, in the form of electrocardiography, echocardiograms, and chest films, is vital to establish a cardiovascular baseline for each patient [7]. These tests can also uncover residual manifestations of $\mathrm{CHD}$, including cardiac chamber dilatation, right or left ventricular dysfunction, and arrhythmias, of which atrial fibrillation is the most common $[6,8]$. As the patient is given nothing by mouth prior to surgery, special attention should be paid to volume status to maintain blood pressure and viscosity close to baseline [9]. Though the American Heart Association argues against the use of prophylactic antibiotics solely to prevent endocarditis in patients whose $\mathrm{CHD}$ is completely repaired, the presence of an atrial baffle or prosthetic valve could increase the risk of infectious endocarditis [10]. The decision to use prophylactic antibiotics to prevent endocarditis during a procedure when antibiotics would not normally be given should be made by the patient's team on a case-by-case basis, and should be considered separately from the antibiotics routinely provided to all patients undergoing certain procedures with a high risk of postoperative infection [11].

While causing less physiological stress compared to open surgeries, the abdominal insufflation of laparoscopic procedures has been shown to produce undesirable hemodynamic effects in patients with CHD. Increasing intra-abdominal pressures as a result of the pneumoperitoneum required to visualize the surgical field can lead to a reduction in cardiac output, as well as hypercapnea, which can progress to pulmonary hypertension [12]. These negative effects can be mitigated by maintaining low intra-abdominal pressures $(8-12 \mathrm{mmHg})$ [13].

Correspondence to: Margaret Mariella, Department of Surgery, University of Louisville School of Medicine, Louisville, KY, USA; E-mail: mccm37@uol.com.br

Received: April 02, 2016; Accepted: July 02, 2016; Published: July 05, 2016 
Intraoperatively, the clinician's goal is to avoid the development of pulmonary hypertension, which can be achieved by maintaining a proper balance between systemic and pulmonary vascular pressures in patients whose physiologic adaptive capacity may be compromised [5]. Although pressure shifts should be anticipated with endotracheal intubation and the induction of anesthesia, close communication with the anesthesiologist and the deliberate choice of anesthetic agents can help minimize these effects [14].

Anesthesia considerations are lesion-specific for the surgically repaired heart, but the most pressing concerns intraoperatively are the presence, size, and direction of flow through intracardiac shunts, pulmonary hypertension, and ventricular dysfunction. In regard to a shunt, the management involves controlling the factors that can influence its direction and magnitude, which can be achieved by adjusting the concentration of inspired $\mathrm{O}_{2}$, optimizing mechanical ventilation, and using pressors or vasodilatory pharmacologic agents. In general, there are no absolutely contraindicated procedures for patients with repaired $\mathrm{CHD}$; these patients can safely undergo noncardiac surgeries as long as adequate preoperative evaluation and preparation, monitoring, and treatment are available to the surgical team.

Special attention, however, must be paid to patients who have undergone atrial baffle operations. In those patients, the right ventricle is connected to systemic circulation and might fail after years of overwork [15]. Every effort should be made to optimize right heart function; preoperative echocardiography evaluation should be made readily available to the anaesthesiologists and surgeons. The team should do everything possible to avoid hypoxemia, hypercarbia, and fluid overload to reduce the chance of acute right heart failure. Due to the potential hypercarbia from laparascopic operations, it might be reasonable to consider open operations in those patients. Arterial lines, central lines, Swan-Ganz catheters, and transesophageal echocardiography might help guide treatment in such situations.

Drugs which cause a dramatic drop in systemic vascular resistance can lead to relative pulmonary hypertension. Inhaled anesthetics, such as Isoflurane, Sevoflurane, and Desflurane, stimulate the sympathetic nervous system and cause increased heart rate and systolic blood pressure lasting around ten minutes, though these could likely be used without issue as long as they are carefully titrated to patient anesthetic needs $[16,17]$. Intubation itself can also result in generalized hypertension, though ensuring that the patient is adequately sedated prior to laryngoscopy can counter this effect [14].

In a compromised heart dependent on preload, clinicians should avoid spinal blocks as these can lead to decreased systemic vascular resistance and decreased preload, particularly in patients with significant cardiac dysfunction. Epidural anesthesia can be regarded as safe to use as long as it is dosed in a slow and controlled fashion and does not produce pronounced vasodilation [12,18,19]. Additionally, the coagulation status of patients receiving epidural anesthesia must be normalized prior to performing a neuraxial procedure, which can be challenging in patients taking anticoagulants.

The use of external central venous pressure monitors in lieu of central venous catheters is preferred in patients whose anatomy predisposes them to arrhythmias, or whose hemodynamic compensatory capacity is incompletely understood [20,21].
Postoperative monitoring and care for adult $\mathrm{CHD}$ patients strives to ensure minimal physiologic stress by preserving euvolemic status and judiciously controlling pain [22].

\section{Conclusions}

Elective laparoscopic surgery can be performed in adult patients with corrected transposition of the great arteries when careful preoperative assessment and intraoperative monitoring accompany standard surgical techniques.

\section{References}

1. Moodie D (2011) Adult Congenital Heart Disease: Past, Present, and Future. Texas Heart Institute Journal 38: 705-706.

2. Maxwell BG, Wong JK, Lobato RL (2014) Perioperative morbidity and mortality after noncardiac surgery in young adults with congenital or early acquired heart disease: a retrospective cohort analysis of the National Surgical Quality Improvement Program database. Am Surg 80: 321-326. [Crossref]

3. Moodie D (2002) Adult congenital heart disease. Ochsner J 4: 221-226.

4. Cannesson M, Earing MG, Collange V, Kersten JR (2009) Anesthesia for noncardiac surgery in adults with congenital heart disease. Anesthesiology 111: 432-440. [Crossref]

5. Seal R (2011) Adult congenital heart disease. Pediatric Anesthesia 21: 615-622.

6. Zomer AC, Vaartjes I, Grobbee DE, Mulder BJM (2013) Adult congenital heart disease new challenges. International Journal of Cardiology 163: 105-107. [Crossref]

7. Cannesson M, Piriou V, Neidecker J, Lehot JJ (2007) Anaesthesia for non cardiac surgery in patients with grown-up congenital heart disease. Ann Fr Anesth Reanim 26: 931-942.

8. Warnes CA (2005) The adult with congenital heart disease: born to be bad?. Journal of the American College of Cardiology 46: 1-8. [Crossref]

9. Gottlieb EA, Andropoulos DB (2013) Anesthesia for the patient with congenital heart disease presenting for noncardiac surgery. Curr Opin Anaesthesiol 26: 318-326. [Crossref]

10. Wilson W, Taubert KA, Gewitz M, Lockhart PB, et al. (2007) AHA guideline: prevention of infective endocarditis. Circulation 116: 1736-1754

11. Difilippo S (2012) Prophylaxis of infective endocarditis in patients with congenital heart disease in the context of recent modified guidelines. Archives of Cardiovascular Diseases 105: 454-60. [Crossref]

12. Eagle SS, Daves SM (2011) The adult with Fontan physiology: systematic approach to perioperative management for noncardiac surgery. Journal of Cardiothoracic and Vascular Anesthesia 25: 320-334. [Crossref]

13. Fujii T, Shirakawa S, Matsuura Y, Yamamoto S, Terai T (2010) Anesthetic managemen of an adult patient with Fontan circulation for laparoscopic surgery. Masui 59: 10251027. [Crossref]

14. Stoelting RK (1979) Attenuation of blood pressure response to laryngoscopy and tracheal intubation with sodium nitroprusside. Anesthesia and Analgesia 58: 116-119. [Crossref]

15. Franzoso FD, Wohlmuth C, Greutmann M, Kellenberger CJ, Oxenius A, et al. (2015) Atrial function after the atrial switch operation for Transposition of the Great Arteries: Comparison with atrial switch and normal by cardiovascular magnetic resonance. Congenital Heart Disease 10.1111/chd.12323. [Crossref]

16. Williams GD, Jones TK, Hanson KA, Morray JP (1999) The hemodynamic effects of propofol in children with congenital heart disease. Anesthesia and Analgesia 89: 1411-1416. [Crossref]

17. Ebert TJ, Musi M (1993) Sympathetic hyperactivity during desflurane anesthesia in healthy volunteers. Anesthesiology 79: 444-453. [Crossref]

18. Singh A, Sarkar D, Kansara B, Sharma KK (2011) Bipolar hip arthroplasty in an adult patient with uncorrected tetralogy of fallot: anesthetic management. Annals of Cardiac Anaesthesia 14: 158-161.

19. Carp H, Jayaram A, Vadhera R, Nichols M, Morton M (1994) Epidural anesthesia for Cesarean delivery and vaginal birth after maternal Fontan repair: a report of two cases. Anesthesia and Analgesia 78: 1190-1192. [Crossref] 
Margaret Mariella BA (2016) Laparoscopic surgery in adults with transposition of the great arteries: A report of two cases

20. Clemmeson L, Knudsen L (2013) Ultrasound guidance during placement of central venous catheter can prevent arrhythmias. Ugeskr Laeger 175: 2498-2499. [Crossref]

21. Pittman JA, Ping JS, Mark JB (2004) Arterial and Central Venous Pressure Monitoring. Int Anesthesiol Clin 42: 13-30.
22. Ammash NM, Connolly HM, Abel MD, Warnes CA (1999) Noncardiac surgery in Eisenmenger Syndrome. American College of Cardiology 33: 222-227. [Crossref]

Copyright: (C2016 Margaret Mariella BA. This is an open-access article distributed under the terms of the Creative Commons Attribution License, which permits unrestricted use, distribution, and reproduction in any medium, provided the original author and source are credited. 